\title{
Support and opposition in an attempted higher education merger
}

\author{
Mats Persson $^{1}$ (D) Magnus Frostenson $^{1}$ (D)
}

Received: 23 August 2020 / Accepted: 8 February 2021 / Published online: 5 March 2021

(c) The Author(s) 2021

\begin{abstract}
The study explores an ultimately unsuccessful merger of three Norwegian public university colleges. It shows how social practices of support for and opposition to the merger were the effects of the intersection(s) between why the merger was necessary and how the proposed merger process was enacted. Support and opposition may change during the merger process, since participants move in and out of positions given how the process unfolds. We relate support and opposition to identity. A merger supports attractive identities if it is consonant with overarching normative ideals of higher education and experienced fairness during the merger process. The findings have implications for how we can better understand and explain why some merger initiatives lead to termination instead of a merger.
\end{abstract}

Keywords Merger $\cdot$ Support $\cdot$ Opposition $\cdot$ Social practice $\cdot$ Higher education $\cdot$ Norway

\section{Introduction}

Higher education mergers are commonly seen as problematic (Pinheiro et al. 2015, pp. 5-7). Often, mergers are described as 'failed' ex post in the sense of not realising some specific expectations linked to, for example, economics, academic activities or governance, management or administrative models (Skodvin 1999). When explaining merger failure (or success, in an opposite sense) recourse is often taken to 'static' explanations such as incompatible organisational cultures (Dahl Norgård and Skodvin 2002; Harman 2002; Harman and Harman 2003), clashing expectations (Skodvin 1999), or other factors, such as geographical distance (Dahl Norgård and Skodvin 2002). Sometimes, failed institutional and strategic leadership or strong governmental intervention are blamed for 'bad' outcomes (Sehoole 2005). Less research exists on higher education mergers that 'failed' in another sense, namely the ones that were initiated and negotiated, but never came about. In such cases, ex post explanations seem problematic since there are no economies of scale, academic activities, et cetera, that can be evaluated. Rather, to understand the outcomes, insights are necessary into the process that was eventually terminated-and how the people involved reasoned and interpreted the contextual realities that were present.

Mats Persson

mats.persson@hiof.no

1 Faculty of Business, Languages and Social Sciences, Østfold University College, Halden, Norway 
This study focuses on the ultimately 'unsuccessful' merger of three Norwegian public university colleges in 2012. Through studying this particular merger, it discusses two important aspects of mergers; first, the study concerns a merger that never came about (at least not including all three partners), second, it provides deeper explanations for support for and opposition to the merger. The research question that the article answers is: 'How can support for and opposition to a merger be explained in a case that never came about?' The study, thus, captures the dynamics of an ongoing merger, providing a more complete explanatory picture, as it stretches beyond merely static explanations given after mergers have ultimately 'failed'.

We see support and opposition as social practices. Social practices'offer(s) a way of analysing human activity which brings together the cognitive and the social aspects of human existence' (Tusting 2005, p. 36). They are not fixed positions but 'a relatively stabilised form of social activity' (Fairclough 2001, p. 231), and relate to how actors construct meaning in everyday life-and in our case a merger process. As the study will show, support and opposition are not absolutes, but relate to underlying reasons for and against the merger and the process in which support and opposition were enacted according to circumstances. Changes from support to opposition (and vice versa) are shifts in social practices rather than absolute positions. As will be explained, the reasons for such changes are primarily identity-related, building on perceived unfairness of the use of power and resources during the process.

The next section contains the background of mergers in higher education and a description of the specifically Norwegian context. A method section follows. Then we provide a presentation and discussion of the social practices of support and opposition, followed by some concluding remarks.

\section{Mergers in higher education}

A common explanation for merging higher education institutions is the intention of achieving larger units, resulting in academic and administrative economies of scale (Dahl Norgård and Skodvin 2002; Mok 2005). The prospects of improving academic performance incentivise the state to organise, and academic institutions to participate in, collaborations and mergers (Ripoll-Soler and de-Miguel-Molina 2014). According to Eastman and Lang (2001, p. 12), merger initiatives are based on a perceived necessity. Hinfelaar (2012, p. 45) classifies the driving forces to merge into two broad categories of "push factors, arising from external pressures which generate defence mechanisms; or pull factors which represent attractive options to organisations'.

Strategically, mergers in higher education have the 'aim of enhancing competitive advantage or mutual growth' (Harman and Harman 2008, p. 99). Mergers are a way of responding to market mechanisms in order to survive the competition (Tirronen and Nokkala 2009). The idea of strategic positioning relates to a neoliberal ideology (Levidow 2002). In this case, higher education institutions operate in a market where 'education is simply another market commodity' (Lynch 2006, p. 1).

As noted by Ylijoki (2014, p. 56), 'one prominent manifestation of the external pressures towards market orientation has been the push for structural changes in higher education'. One type of structural change is that of mergers (Tirronen and Nokkala 2009), where a merger resulting in a unitary structure is the closest form of higher education collaboration (Harman and Harman 2003). Accepting the fact that higher education institutions 
operate in a global market, "competition in higher education comes from domestic and foreign universities/colleges, private institutions and the increasing number of "virtual universities"' (Chandler 2013, p. 244).

In Norway, mergers have also been a means for university colleges to achieve university status. The Norwegian binary system distinguishes the non-university sector of university colleges from the university sector. However, the binary system is under pressure. It is sometimes referred to as a 'flexible and transparent' (Skodvin 2014, p. 4) because if university colleges fulfil certain national academic standards and criteria they can achieve university status. Some higher education institutions therefore 'started to behave like autonomous players in a competitive marketplace created by the government and explicitly wanted university status' (Kyvik and Stensaker 2015, p. 40). Accordingly, merger processes have been a 'key ingredient of Norwegian higher education in the last 20 years' (Kyvik and Stensaker 2015, p. 39) and they have become an increasingly common way of restructuring higher education institutions (Kyvik and Stensaker 2013, p. 1; Skodvin 2014, p. 3). Over the years, the governmental approach has shifted from 'forced (mid-1990s) to voluntary (2007-2014) back to "forced voluntary" mergers (2015-onwards)' (Pinheiro et al. 2015, p. 10; Harman and Harman 2003). In a series of recent voluntary merger initiatives of Norwegian higher education institutions, a few did not succeed. To understand why, it is necessary to go into the merger process of the university colleges.

\section{Data and methods}

This study involves three Norwegian public university colleges. The university colleges are geographically located in three different counties and each university college has between one and three campuses. One of the university colleges initiated a research project to study the merger process, and the first author was given the opportunity to participate as a $\mathrm{PhD}$ student (Persson 2015). The aim of the project was to contribute to the understanding of higher education mergers. However, the merger was terminated and the aim shifted to focusing on what caused the termination. Interviews were the prime source of information. 29 in-depth interviews were made in the period March-May 2012.

The respondents represented all three partners and included participants from the steering committee, project secretariat and others (Table 1).

All interviews were tape recorded and transcribed. They were open-ended with the intention to 'explore people's views of reality and allow the researcher to generate theory' (HesseBiber and Leavy 2011, p. 103). The respondents primarily reflected on their experiences of the merger process and why the merger was terminated. In addition, probes (Merriam and Tisdell 2016, p. 122) were used when there was a need for follow-up questions. Through the interviews, discursively constructed social practices could be identified in the context of the merger (Tusting 2005). Support and opposition were expressions of ideational and normative judgements in light of the contextual realities of the merger. They were 'negotiated' experiences of the everyday life that the merger process involved (Wenger 1998). Key events in the transcripts, describing the merger process and why the merger was terminated, were identified, coded and inductively developed and understood as social practices; supporting the general idea of the merger, supporting the merger process, opposing the general idea of the merger and opposing the merger process. Each articulates particular ways of using language reflecting social relations of formal and informal groups within and between the three university colleges (Fairclough 2003). Further analysis of these practices revealed 
Table 1 Respondents by category

\begin{tabular}{|c|c|}
\hline Steering Committee & University college \\
\hline Rector/Chairman of the board & A \\
\hline University College Director & A \\
\hline Member of the board & A \\
\hline Member of the board & A \\
\hline Trade union representative & $\mathrm{A}$ \\
\hline Student leader & A \\
\hline Rector & B \\
\hline University College Director & $\mathrm{B}$ \\
\hline Chairman of the board & $\mathrm{B}$ \\
\hline Member of the board & $\mathrm{B}$ \\
\hline Trade union representative & $\mathrm{B}$ \\
\hline Rector/Chairman of the board & $\mathrm{C}$ \\
\hline University College Director & $\mathrm{C}$ \\
\hline Member of the board & $\mathrm{C}$ \\
\hline Member of the board & $\mathrm{C}$ \\
\hline Trade union representative & $\mathrm{C}$ \\
\hline Student leader & $\mathrm{C}$ \\
\hline Project secretariat & University college \\
\hline Director of Organisation and Communication & A \\
\hline Human Resource Manager & $\mathrm{A}$ \\
\hline Chief Communications Officer & $\mathrm{B}$ \\
\hline Human Resource Manager & $\mathrm{B}$ \\
\hline Chief Communications Officer & $\mathrm{C}$ \\
\hline Human Resource Manager & $\mathrm{C}$ \\
\hline Others & University college \\
\hline Representative of academic staff & $\mathrm{A}$ \\
\hline Communication advisor* & $\mathrm{C}$ \\
\hline Chief Financial Officer* & $\mathrm{C}$ \\
\hline Director of Academic Affairs \& Research* & $\mathrm{C}$ \\
\hline Member of the board* & $\mathrm{C}$ \\
\hline Representative of academic staff & $\mathrm{C}$ \\
\hline
\end{tabular}

*Interviews conducted before the decision to terminate the three-party merger

underlying reasons for support and merger in the respective social practices. For example, identity-related arguments of opposition suggested that, as the merger developed, it did not take into account expectations of fair treatment of some participants.

Another source of data was documents produced during the merger process consisting of two preliminary reports, five workgroup reports with additional consultative statements and a final report with its consultative statements, spanning a period from 2010 to 2012. The documents were extensively read and re-read (Flick 2015). They were analysed using qualitative content analysis and became 'evidence in support of the findings' (Merriam and Tisdell 2016, p. 181) in the transcripts. That is, the documents could give further information and understanding of the central themes that the social practices focused on. Furthermore, the 
new direction of the study involved some ethical concerns that included communicating the new focus of the study (the termination of the merger). It also involved securing informed consent and guaranteeing anonymity and confidentiality, as well as the right to withdraw from the study at any point of time. In the following section, we present and discuss the identified social practices.

\section{Social practices of support and opposition}

\section{Supporting the general idea of the merger}

Looking at the merger case, general arguments used by various actors resembled the ones mentioned earlier. The ideas about a common future university related to strategy, a better competitive position in recruiting students, staff and research funding. The arguments built on a competitive idea of survival, requiring collaboration. To this, current resources, such as developed $\mathrm{PhD}$ programmes were used as arguments for why the new joint structure would be well positioned, to the benefit of all.

Various actors referred to the competitive context, a university market that required action to be taken. Higher education institutions were understood as competitors in a global market. A respondent from University College A explained: 'There is a change in the higher education sector from a protected monopoly to a situation where higher education institutions are exposed to competition. The competition is for students, staff and research funds'. This quote reveals a very general reason for why the three higher educations should merge, namely to secure the resources of students, staff and research funds. Competition for students involves competition for a high number of students and, from a qualitative aspect, the best students.

It is, thus, a matter of quantity and quality, as 'better' students guarantee throughput (the number of graduating students), where 'better' refers to grades from upper secondary school. The higher the number of graduating students, the larger the sum paid to the higher education institution. Better students are also presumed to get higher grades, which increases the status of the higher education institution.

Competition for staff relates to academic staff. Securing the 'best minds' will be advantageous. 'Best' in this case refers to the three main tasks of an academic employee. Firstly, pedagogically skilled staff secure a stable number of graduating students. The responsibility for throughput lies with the lecturer rather than the student. Secondly, 'best' means productive researchers, publishing articles in highly ranked journals and obtaining research grants. Here too there is a link to remuneration. Thirdly, the 'best' academics appear in the media as experts. They give public talks and are visible in the public domain. It also serves as a means of marketing the workplace, relating to status.

Status is important. To have the best students, the best academics and several well-funded research projects increases the status of the higher education institution. Operating in a global market, status is pivotal to winning the competition for resources. Achieving university status is another way of becoming more competitive in the education market.

The general argument relates to all these aspects. It suggests that if we do not merge, we will lose out in the competition for students, staff and research funding. This is illustrated by a respondent from University College B: 'It became more obvious for many of us that there is a risk in standing alone as an institution in the landscape we now see developing with globalisation, internationalisation and international focus'. The risk of marginalisation in a competitive market is a push factor that makes it necessary to merge. 
Relatedly, the argument of support contains a discursive construction of a particular 'we', including all three involved university college institutions. 'We' becomes construed as 'the merged university colleges' and 'they' are the competing higher education institutions. As we shall see below, 'we' was constructed in another way as the process went on. However, firstly, 'we' referred to one single entity, the merged university college. As an argument in support of the merger, it relates to a general idea of 'us', 'communion' or 'sitting in the same boat' - a joint understanding of belonging to a common solution to a wider general problem (and, thus, an argument in support of the merger). Thus, the merger becomes the solution to the problems of the individual institutions. One example of how the common solution would benefit all came from a respondent at University College A: 'We have always thought that these $\mathrm{PhDs}$ will be the merged university colleges' $\mathrm{PhDs}$, and that it is a gain for all involved institutions to bring them into the merger', The use of 'we' referred to the merged university colleges. It presupposed a construction of a merged entity following (a future) decision to merge, as if the decision had already been taken. To materialise a 'we', there had to be a merger, although no formal decision to merge had been taken at that point.

A better competitive position, better common $\mathrm{PhD}$ programmes, and so on, were arguments relating to the reward of becoming a university. The attractiveness and suggested (or even promised) outcomes of a future university become a general argument and a pull factor for a merger. One respondent at University College $C$ argued: 'if you decide to merge, a logical consequence is to become a university'. At the time of the merger negotiations, university colleges could apply for accreditation to become fully-fledged universities if certain standards were met. These standards included offering master's degrees in at least five different areas and PhDs in at least four different fields. On your own, this was much more difficult to achieve. A respondent from University College $C$ explains that 'the way I see it the reason for the merger is to become a university. Because then you'll be one legal unit. And you can count the PhDs and then you'll be more attractive to researchers, teachers and students'. In principle, it was possible to merge and remain a joint university college, but the university status as such became an argument and a way of becoming more competitive in the education market, with the $\mathrm{PhD}$ programmes described as the means to that goal.

\section{Supporting the merger process}

As the merger process went on, the hopes, rewards and promises described previously were in one way or the other to take shape. How to become a single organisation had to be decided and involved negotiations. As mentioned above, four different $\mathrm{PhD}$ programmes are one of the criteria for university status. Most Norwegian university colleges do not have the capacity to develop these programmes alone. A merger is thus a way of joining forces to share costs.

During the merger process, University College A already had a $\mathrm{PhD}$ programme and another one under development. University College B had two programmes underway and University College $\mathrm{C}$ had neither an established programme nor any under development. That is, four PhD programmes were either already established or under development during the merger process. In the social practice of supporting the merger process, these $\mathrm{PhD}$ programmes would benefit from the merged institution, since a considerable amount of money had already been invested in their development and they would make the path to becoming a university shorter. To some, it was difficult to understand how anyone could disagree with this. A respondent from University College B claimed: 'the fact that we establish and seek accreditation for $\mathrm{PhDs}$, isn't that an advantage for 
everyone in the end? How could that become a thing that made this crash?' For this respondent the process of how these $\mathrm{PhD}$ programmes were developed did not matter, at least not in the sense that it should matter to University College C. Questioning the process of developing PhDs was incomprehensible because they were seen as an advantage for everyone that was part of the constructed 'we' of the new higher education institution. As we shall see, to University College $\mathrm{C}$, the relevance of this process was high. The 'supporters', however, dismissed opposition to the process. Since the university colleges were joining forces anyway, becoming one institution, the issue of an 'unfair' process or outcome was considered irrelevant.

Another issue was the location of the faculty management. Faculty management should be located in the 'best' academic milieus, understood as where the PhD programmes were (or were planned to be) developed and located. Any objections to how the process of deciding faculty management location unfolded were dismissed, once again on the premise that after the merger there would only be one institution anyway. A respondent from University College B put it this way:

A faculty will benefit from a $\mathrm{PhD}$. I mean all faculties are represented in the three old institutions. An example, a $\mathrm{PhD}$ in health science will be just as associated with the milieu at [University College C] and [University College A] as it will be at [University College B] where faculty leadership was suggested [to be] located.

Where faculty management was located within the merged university college was subordinate. The view, rather, was that whatever the decision, it was to the benefit of all.

To sum up, the social practice of support during the process contained the idea that the development of $\mathrm{PhD}$ programmes was instrumental to achieving the goal of becoming a university, to the benefit of all. Faculty managements were to be located where the $\mathrm{PhD}$ programmes were located, since they represented the 'best' academic milieus. The focus was on why the university colleges should merge (competitive reasons, university status, et cetera), making the issue of how the process developed and what its outcomes were less relevant. It also shows how supporters of the merger may have been unaware of (or may have disregarded) which resources everyone brought into the process (e.g. already existing or planned PhD programmes) and how these would likely affect the process and the outcome. For these 'supporters', their view of reality was 'common sense'.

\section{Opposing the general idea of the merger}

In finding opposition to the general ideas behind the merger, one could, as a simplification, find arguments negating the preceding ones about the competitive context, the construction of 'we' and the reward of becoming a university. Such general opposition need not, however, be formulated in the form of active negation (e.g. no reward in becoming a university). It can also be a matter of finding limited relevance of the general arguments or descriptions of reality. For example, persons opposing the merger spoke incredulously about the 'higher education market'. As a respondent at University College A explained:

This metaphorical debate about mergers being some kind of industry project. It's linked to the idea that there's a market out there. With buyers and sellers, and that there's increasingly fierce competition. It's as if we were selling products. But that is simply not true. 
Thus, the construction of a competitive market was not accepted as an adequate representation of the higher education realities.

Further, to some, the merger was a possibility but not a necessity. The risk of a university college being closed down if the merger did not continue was seen as unrealistic scaremongering. One respondent from University College B rejected the idea that '...either we need to do something or else we co-bust':

Colleges are not in that situation. [...] Because everyone sees that we are going to survive as an institution, even if we don't merge. I think the anxiety for the unknown was more communicated than the advantages of a merger.

The necessity to merge in order to survive expressed an idea of 'do or die'. When confronted with this, one respondent from University College A said:

[P] eople don't buy that. If we don't become a university, if we don't merge and become very large and strong, all students will disappear abroad. No one believes that. It's something about the credibility in the argument that sometimes crackles.

Here, the argument put forward in the social practice of support-that merger as the only way of survival-is regarded as nonsense. It is not credible. The respondent polarises the viewpoints by saying that 'all students will disappear abroad' if there is no merger, in this way implying that that is what supporters mean. This is a strawman argument, as it is not realistic, but it fills a rhetorical function as it constructs an opposing viewpoint that is clearly refutable.

In the social practice of opposition, the idea of becoming a university was also problematised from a qualitative standpoint. In answering the question about whether the university ambition is a good argument for a merger, a respondent from University College C replied; 'no, I don't think so. I don't want to be a second-rate university. I'd rather be a good university college'. From a normative standpoint, if universities and university colleges serve two different purposes in the higher education sector, where university colleges focus on regional short-cycle vocational educations and teaching, rather than research, the vantage points are not necessarily compatible. It may actually be possible for a university college (or three of them) to be qualitatively 'better' than a university, given its vocational mission. If the traditional vocational education of university colleges is held in esteem, people may identify more with the values and purpose of a university college, which renders the ambition to become a university meaningless. This normative aspect relates to the underlying values of a university college and a university, respectively. Providing vocational education is what the university college 'should' do. This echoes the tension between academic norms and ideals related to research on the one hand and traditional vocational education on the other (Kyvik and Skodvin 2003; Tight 2015). Opposition is based on an idea of a binary system in the higher education sector where universities and university colleges are regarded as equal but different. They do different things and should be kept apart.

Summing up, opposition does not only take the shape of pure negation of the arguments for the merger. It also consists of an alternative view of reality than the 'education market' perspective as well as a denial of the inevitability of being on the losing team if continuing on your own. The attractiveness of the reward of becoming a university is doubted, since a fear exists as to which kind of university the merged university colleges will become. Further, the normative idea of what a university college is and should be matters. Thus, there are also signs that the idea of the merger - to become a university-is rejected. However, to understand opposition further, and why the merger finally did not come about as planned, an understanding of the opposition developed during the merger process is necessary. 


\section{Opposing the merger process}

In particular, two process aspects stand out that could be summarised as a competition for resources and an attachment to organisational identity, which entailed a specific construction of 'we' in relation to others (cf. previous reasoning).

When referring to a competition for resources, however, the issue was not primarily competition for students, staff and research funding. Rather, the already mentioned $\mathrm{PhD}$ programmes had high significance, as well as the future geographical location of the faculty management, and the allocation of financial resources. What was at stake was, in all cases, related to securing one's own university college's interests.

A respondent from University College C linked the university ambition to the development of PhDs, saying that 'when they [University College A and B] rushed the development of their PhDs it led to conflict'. It is worth noticing that the respondent works at the university college that did not develop any $\mathrm{PhD}$. The respondent also contended that 'resources had to be drawn from other places'. This included financial resources, and by 'other places' the respondent meant both taking resources from bachelor programmes to finance the $\mathrm{PhD}$ programmes and to redistribute financial resources between the three merger partners. The respondent concluded that when a faculty structure was suggested where '[faculty] management must be located where the PhDs are located', the imbalance between the merger partners became so obvious that '[University College C] gradually developed much resistance to the merger idea'. Thus, this was something that emerged during the process, and it affected how representatives of University College C came to evaluate the entire process, including the development of PhDs and the allocation of resources.

The uneven balance became even more apparent when University College A and B that had started developing their $\mathrm{PhD}$ programmes continued to do so after the merger process had started. That was seen as a deal breaker, since the $\mathrm{PhD}$ programmes were to be developed jointly. A respondent at University College $\mathrm{C}$ explains:

From my point of view, it would be natural for the rectors to say: let's freeze this

[PhD programmes] until we have consolidated our positions and considered a pre-

liminary strategy for the new institution and how this fits in there, and how the division of work should be organised.

In criticising the merger partners, the respondent constructs opposition based on how the process progressed. Instead of seeing the development of $\mathrm{PhD}$ programmes as a common good benefiting all three merger partners on the way to becoming a university, she proposes a hiatus until the merger is a reality.

What we see is that how, in terms of how the merger process was enacted, constituted the basis for the opposition. This also involved the location of the faculty management. If the logic of the 'supporters' was followed, the faculty management would be located at the geographical site where the $\mathrm{PhD}$ programmes were developed. This would be a disadvantage to University College $\mathrm{C}$ since it lacked $\mathrm{PhD}$ programmes under development. The allocation of the faculty managements implied strategic positioning and was an expression of competition between the merger partners. In addition, and relating to financial issues, the $\mathrm{PhD}$ programmes would be (co-)financed by an institution that did not benefit from them in any other sense than being part of a university that had $\mathrm{PhD}$ programmes.

As the process continued, tensions rose. University College $\mathrm{C}$ finally opted out and noted how the two university colleges developing $\mathrm{PhD}$ programmes took advantage of 
University College C's financial assets. A respondent at University College C gives voice to this perceived imbalance; 'there was a lot of power on the other side, and there was a lot of money on this side'. Remember, University College $C$ neither had, nor was in the process of developing, a PhD programme. The criticism of spending money on developing $\mathrm{PhD}$ programmes could also be linked to a lacking will of seeking university status. When talking about what University College A and B wanted from University College C, the respondent simply answered 'our money' and continued 'it sounds banal and simple but I think it was that simple'.

Something that materialised was a ('new') construction of 'we', relating to organisational identity. It was a question of whether the merger was more like an acquisition than a merger of equals, where the distinct characteristics of one's own organisation would be lost. Here, positioning oneself was seen in relation to the merger partners rather than to other higher education institutions. The fear of being internally marginalised was a driving force for positioning, and positioning was necessary, as one respondent from University College C admits: 'You may very well use the word naive. We have not invested enough resources on positioning ourselves at the forefront of this'. When opposing the merger the concept of 'we' was used in reference to one's own university college. How a respondent at University College $\mathrm{C}$ talks about the development of $\mathrm{PhD}$ programmes is a typical example: 'then we learned that they had continued the development of their PhD programmes despite the fact that we were in a merger process, and they did not inform us about that. In a way we felt tricked'. The use of 'we' and 'them' increased the polarisation and differences between the merger partners. Instead of visualising a common future with a shared goal, the ongoing merger process was decisive for the 'we' that was constructed. From an identity perspective, this contributed to cementing the rejection of the idea of becoming a university.

\section{Understanding why and how}

Support and opposition developed as social practices relating to 'why- and how-issues'. However, the arguments for and against the proposed merger were not fixed and decisive during the process, but partly reconstructed given how the process developed. An imbalance between the partners arose during the process, which consequently led to the marginalisation of one of them. Even though it was sympathetic to the university ambition and had an interest in developing $\mathrm{PhD}$ programmes, the use of its financial resources in the development of $\mathrm{PhD}$ programmes and the location of the faculty management were not in its interest. This resulted in a shift from focusing on why they should merge to how the merger process was enacted, and consequently a shift from support to opposition (among representatives from University College C).

An observation is that representatives from University College A and B that went on with the merger had a tendency to treat the merger process as subordinate to the overarching 'why-issue'. That is, the construction of a new university involved a new 'we', making individual concerns about the process irrelevant. These persons suggested that it was superfluous or meaningless to argue about 'unfair' processes or outcomes. The end justified the mean, on a somewhat crude interpretation. The premise was, of course, that the promises and arguments for the merger were attractive enough. However, in practice, not all participants shared this view, and the problem was hardly dealt with in any reasonable manner. The opposition was dismissed with reference to the 'reward' of reaching a 
common university status. That also entails underestimation of the relevance of the process for the ultimate outcome.

Moreover, support and (perhaps to a higher extent) opposition were constructed as the process went by. Importantly, opposition against how the process unfolded was obvious, but also that some actors re-evaluated the 'why-issue' as the process proceeded. That is, the arguments for why the merger was beneficial were not fixed during the entire process, but were reconstructed as it developed, based on process experiences. To understand why the merger did not reach its full potential (including all three parties) it is important to point to the dynamics of the process and the process experiences' effects on the general understanding of the merger. Becoming a university, for example, was attractive from the outset, but becoming an insignificant part of that university, or even a second-rate university, an understanding partially developed during the process, weakened one of the arguments for the merger.

Another example of change from support to opposition was the proposed faculty location. At one point, it was proposed that the faculty management should be located at University College $\mathrm{C}$, and not where the $\mathrm{PhD}$ programme was being developed—at University College A. In this case, the faculty developing the $\mathrm{PhD}$ programme (at University College A) demanded that faculty management be located to them, otherwise they would oppose the merger. As the merger process continued and it was proposed that the faculty management should be located at University College A after all, the social practice changed back to support. This is an example of the fluid character of support and opposition. During the process, it did not just go from one thing to another, but it could also take a reverse route following new developments.

\section{Conclusions}

How, then, can support for and opposition to a merger be explained in a case that never came about? As illustrated, this is a case that never developed according to intentions, as a three-party merger. We have pointed to aspects of opposition, general but also-and perhaps of even more importance-during the merger process. Explanations for the opposition could be material, a struggle for power and resources. Our argument, however, goes beyond seeing mergers as zero-sum games (cf. Harman 2002, p. 107). Rather, the ongoing construction of fair and reasonable outcomes during the merger process must be taken into account. A suggestion of how to understand opposition is given in Table 2.

Essentially, opposition exists both as a general phenomenon and as one arising during the process. Overall, it is a matter of identity, 'a collective, commonly-shared understanding of the organization's distinctive values and characteristics' (Hatch and Schultz 1997, p. 357), but enacted differently in relation to the general idea of the merger and the process that unfolds. The general opposition-found among representatives from all merging partners-relates to how actors define themselves and preferred normative ideals. For example, not all identify with market ideas or the ideal of becoming a university. That also reflects the contextual nature and embeddedness of sensemaking (Weber and Glynn 2006). However, as a local and ongoing practice, participants try to make sense of the process in relation to each other, and the decisive form of opposition arises during it. As said, in a more direct sense it concerns power and resources. Arguably, however, it is also a matter of identity in the sense of what kind of merging partner one wants to be and the perception of whether one gets fair treatment or not. During the process, it turns out who is'equal' and 
Table 2 Explanations for opposition

\begin{tabular}{lcc}
\hline & General opposition & Merger process opposition \\
\hline $\begin{array}{l}\text { Explanation for opposi- } \\
\text { tion }\end{array}$ & $\begin{array}{c}\text { Identity - 'who should we be in } \\
\text { relation to the idea of a higher } \\
\text { education market and of univer- } \\
\text { sity status?' }\end{array}$ & $\begin{array}{c}\text { Identity - 'what kind of partner do we } \\
\text { become in the merger?' (merger of equals } \\
\text { or acquisition) }\end{array}$ \\
Underlying factors & $\begin{array}{c}\text { Normative ideals of university } \\
\text { (college) mission and function } \\
\text { 'Location' of opposition }\end{array}$ & $\begin{array}{c}\text { Understanding of fairness in relation to the } \\
\text { use of power and resources }\end{array}$ \\
& $\begin{array}{c}\text { University College C (at some point also } \\
\text { University College A) }\end{array}$ \\
\hline
\end{tabular}

who is 'taken over'. University College C ends up in the latter category and opts out. Experienced fairness (or unfairness) in terms of how power and resources are used becomes the litmus test of support or opposition. It also tends to affect the general views about whether to merge or not.

Such an understanding also points to the wider phenomenon of organisational change failure, described as 'an organization's deviation from goals and outcomes that are expected and desired from organizational change' (Schwarz et al. 2021, p. 162). In this case, this is a 'failure' only in an inter-organisational sense, in relation to a joint goal of merging and (possibly) achieving a future university status. Identity perceptions both before and during the process of change are explanatory factors particularly relevant in the inter-organisational case with strong mandates of the involved merging partners. The general purpose of the merger and the way resources are used must resonate with the participants' ideals and understandings of fair use during the process.

Thus, support and opposition are constructed based on underlying ideals and perceptions of the process. They are not fixed subject positions. Rather, it is within the merger process that people make sense of the situation, and see themselves within it (Ylijoki and Ursin 2013). Perceiving people as fixed 'supporters' or 'opponents' is a reductionist idea that conceals the true complexity of how constructions of meaning affect, and are affected by, social practices.

It is most likely true that mergers sometimes fail due to incompatible organisational cultures (Dahl Norgård and Skodvin 2002; Harman 2002; Harman and Harman 2003), clashing expectations (Skodvin 1999), geographical distance (Dahl Norgård and Skodvin 2002), or bad strategic leadership (Sehoole 2005). In our case, however, there is no ex post fixed explanation for 'failure'. Rather, we see a (partly) terminated process of merging organisations where decisive explanations are found within the dynamics of the merger process.

The findings have implications for how we can better understand and explain why some merger initiatives lead to termination instead of a merger. Generally, and of high relevance to managers in higher education institutions, merger processes and processes in general require a thorough understanding of how different constituents perceive of the use of power and resources. And, particularly so in terms of perceived fairness during change processes, since this is a central aspect decisive of how a process will develop, in the direction of 'success' or 'failure'.

Arguably, some limitations deserve attention. Given the methodology, we get limited insights into how different actors affected each other during the process, for example through teaming up against another part. That also underscores the need for an increased understanding of power relations in mergers. Rigorous process studies may be a remedy. In 
addition, our study focuses on a decentralised micro context where agents influence which activities they engage in and how they organise them (substantive and procedural autonomy, see Altbach et al. 2005). The results are not necessarily transferable to other contexts with lower degrees of decentralisation. In such cases, more focus should be on central (higher education authorities') decision-making. This is also a signal to researchers to be specific about the contextual nature of higher education mergers.

\section{Funding Open access funding provided by Østfold University College.}

Open Access This article is licensed under a Creative Commons Attribution 4.0 International License, which permits use, sharing, adaptation, distribution and reproduction in any medium or format, as long as you give appropriate credit to the original author(s) and the source, provide a link to the Creative Commons licence, and indicate if changes were made. The images or other third party material in this article are included in the article's Creative Commons licence, unless indicated otherwise in a credit line to the material. If material is not included in the article's Creative Commons licence and your intended use is not permitted by statutory regulation or exceeds the permitted use, you will need to obtain permission directly from the copyright holder. To view a copy of this licence, visit http://creativecommons.org/licenses/by/4.0/.

\section{References}

Altbach, P., Berdahl, R., \& Gumport, P. (Eds.). (2005). American higher education in the twenty-first century: social, political, and economic challenges. Baltimore: Johns Hopkins University Press.

Chandler, N. (2013). Braced for turbulence: understanding and managing resistance to change in the higher education sector. Management, 3(5), 243-251. https://doi.org/10.5923/j.mm.20130305.01.

Dahl Norgård, J., \& Skodvin, O.-J. (2002). The importance of geography and culture in mergers: a Norwegian institutional case study. Higher Education, 44(1), 73-90.

Eastman, J., \& Lang, D. (2001). Mergers in higher education: Lessons from theory and experience. Toronto: University of Toronto Press.

Fairclough, N. (2001). The dialectics of discourse. Textus, 14(2), 231-242.

Fairclough, N. (2003). Analysing discourse: Textual analysis for social research. New York: Routledge.

Flick, U. (2015). Introducing research methodology: A beginner's guide to doing a research project (2nd ed.). Thousand Oaks: Sage.

Harman, K. (2002). Merging divergent campus cultures into coherent educational communities: challenges for higher education leaders. Higher Education, 44(1), 91-114.

Harman, G., \& Harman, K. (2003). Institutional mergers in higher education: lessons from international experience. Tertiary Education and Management, 9(1), 29-44.

Harman, G., \& Harman, K. (2008). Strategic mergers of strong institutions to enhance competitive advantage. Higher Education Policy, 21(1), 99-121.

Hatch, M. J., \& Schultz, M. (1997). Relations between organisational culture, identity and image. European Journal of Marketing, 31(5-6), 356-365.

Hesse-Biber, S. N., \& Leavy, P. (2011). The practice of qualitative research (2nd ed.). Thousand Oaks: Sage.

Hinfelaar, M. (2012). Emerging higher education strategy in Ireland: amalgamate or perish. Higher Education Management and Policy, 24(1), 33-48.

Kyvik, S., \& Skodvin, O.-J. (2003). Research in the non-university higher education sector - tensions and dilemmas. Higher Education, 45(2), 203-222.

Kyvik, S., \& Stensaker, B. (2013). Factors affecting the decision to merge: the case of strategic mergers in Norwegian higher education. Tertiary Education and Management, 1-15. https://doi. org/10.1080/13583883.2013.805424

Kyvik, S., \& Stensaker, B. (2015). Mergers in Norwegian Higher Education. In R. Pinheiro, L. Geschwind, \& T. Aarevaara (Eds.), Mergers in higher education - The experience from Northern Europe. Drodrecht: Springer.

Levidow, L. (2002). Marketizing higher education: neoliberal strategies and counter-strategies. In K. Robins \& F. Webster (Eds.), The Virtual University? Knowledge, markets and management (pp. 227-248). Oxford: Oxford University Press. 
Lynch, K. (2006). Neo-liberalism and Marketisation: the implications for higher education. European Educational Research Journal, 5(1), 1-17.

Merriam, S. B., \& Tisdell, E. J. (2016). Qualitative research: A guide to design and implementation (4th ed.). San Francisco: Jossey-Bass.

Mok, K.-H. (2005). Globalization and educational restructuring: university merging and changing governance in China. Higher Education, 50(1), 57-88.

Persson, M. (2015). The construction of support and opposition: a study of an attempted higher education merger. Karlstad: Karlstad University Studies.

Pinheiro, R., Geschwind, L., \& Aarevaara, T. (2015). A world full of mergers: The Nordic countries in a global context. In R. Pinheiro, L. Geschwind, \& T. Aarevaara (Eds.), Mergers in higher educationThe experience from Northern Europe. Drodrecht: Springer.

Ripoll-Soler, C., \& de-Miguel-Molina, M. (2014). Are mergers a win-win strategic model? A content analysis of inter-institutional collaboration between higher education institutions. Tertiary Education and Management, 20(1), 44-56.

Schwarz, G. M., Bouckenooghe, D., \& Vakola, M. (2021). Organizational change failure: framing the process of failing. Human Relations, 74(2), 159-179.

Sehoole, M. T. C. (2005). The politics of mergers in higher education in South Africa. Higher Education, 50(1), 159-179.

Skodvin, O.-J. (1999). Mergers in higher education: success or failure? Tertiary Education and Management, 5(1), 63-78.

Skodvin, O.-J. (2014). Merger as an instrument to achieve quality in higher education-rhetoric or reality? Paper presented at the EAIR 36th Annual Forum, Essen, Germany.

Tight, M. (2015). Theory development and application in higher education research: the case of academic drift. Journal of Educational Administration and History, 47(1), 84-99. https://doi. org/10.1080/00220620.2015.974143.

Tirronen, J., \& Nokkala, T. (2009). Structural development of Finnish universities: achieving competitiveness and academic excellence. Higher Education Quarterly, 63(3), 219-236.

Tusting, K. (2005). Language and power in communities of practice. In D. Barton \& K. Tusting (Eds.), Beyond communities of practice: Language power and social context (pp. 36-54). Cambridge: Cambridge University Press.

Weber, K., \& Glynn, M. A. (2006). Making sense with institutions: context, thought and action in Karl Weick's theory. Organization Studies, 27(11), 1639-1660.

Wenger, E. (1998). Communities of practice: Learning, meaning, and identity. Cambridge: Cambridge University Press.

Ylijoki, O.-H. (2014). University under structural reform: a micro-level perspective. Minerva, 52(1), 55-75. https://doi.org/10.1007/s11024-014-9246-1.

Ylijoki, O.-H., \& Ursin, J. (2013). The construction of academic identity in the changes of Finnish higher education. Studies in Higher Education, 38(8), 1135-1149.

Publisher's note Springer Nature remains neutral with regard to jurisdictional claims in published maps and institutional affiliations. 